KeMAS 16 (3) (2021) 377-384
Jittp:/journal.unnes.ac.id/nju/index.php/kemas

\title{
The Impact Langgam's Music Instrumental of Javanese Style to Reduce Anxiety and Labor Pain
}

Emy Suryani ${ }^{1 凶}$, Lutfiana Puspita Sari ${ }^{1}$, and Irene Natalia Suci Ardhila ${ }^{2}$

${ }^{1}$ Midwifery Major, Health Polytechnic Ministry of Surakarta

${ }^{2}$ Delivery Room of Surakarta’s Hospital

\section{Article Info}

Article History:

Submitted March 2020

Accepted September 2020

Published March 2021

Keywords:

Anxiety, Music, Intru-

mental, Pain, Labor,

DOI

https://doi.org/10.15294/

kemas.v16i3.23876

\begin{abstract}
Anxiety is a psychological factor that contributes to labor pain. The prevalence of mothers who experience anxiety before labor is $10-50 \%$. Intervention to reduce anxiety and increase relaxation by listening to music. The research purpose is to analyze labor anxiety and pain to the group given intervention Langgam, music instrumental of Javanese style, with midwifery care routine. The research method used by Randomized Controlled Trial Experimental is an experimental study using random procedure to allocate various research factors to the research subject, so only the chance factor places the research subject into the intervention or control groups. There are 60 research subjects, the primiparous mothers, in the labor phase in Surakarta Hospital from December 2nd, 2019 - February 27th, 2020, with simple random sampling. Data analysis by Mann Whitney test and independent simple T-test. Result: For anxiety level, there is a significant difference between Javanese style Instrumental music (mean: 33.9 ) and midwifery care routine (mean: 37.9) with $\mathrm{p}$ value $=0.000$. For labor pain, there is a significant difference between Javanese style Instrumental music (mean: 64.83) and midwifery care routine (mean: 76.13) with $\mathrm{p}$ value $=0.000$. Conclusion: Langgam Music Instrumental of Javanese Style can reduce labor anxiety and pain in primiparous mothers in the first phase of active labor.
\end{abstract}

\section{Introduction}

Childbirth is a beautiful thing and is an important event and will probably be memorable for every woman. Normal childbirth is a labor contraction, which is a process of cervical dilatation and opening. And this natural process causes labor pain for every woman who will give birth. The labor pain is physiological. And this is not a sign of danger of labor(Aksoy, 2016). The prevalence of normal delivery process is around $85-90 \%$. Only 10 $15 \%$ of deliveries end in a cesarean section. Based on WHO data, about $40 \%$ of the cesarean sectio reason is experiencing labor fear and pain. Each mother has a different body response to the perception of labor pain. Mothers who experience excessive anxiety and stress during the labor process will harm the delivery process and the baby being born. Mother's anxiousness will flow through the placenta and cause fetal distress of the baby being born. So the baby has a low Apgar score(Abbasi, 2020).

Some birth mothers will feel fear and anxiety during labor. The high anxiousness experienced by birth mothers will improve responsiveness to labor pain. Even experienced postpartum depression (Floris, 2017). Anxiety during pregnancy has many side effects, both for the mental health of the mother and the outcome of delivery, as well as being a risk factor for postpartum depression. Anxiety and stress during pregnancy are associated with fetal heart rate and motor activity, preterm delivery, and infant behavior. Postpartum anxiety is linked to low self-esteem in the mother, and can have long-term negative consequences leading 
to delayed mental development in the child (Rados, 2018). Fear of childbirth is commonly framed as a phenomen on within the domain of anxiety, and clinical descriptions of childbirth fear are often characterized by symptom expressions resembling those of various emotional disorders. The physiological aspects of fear and anxiety include responses such as palpations, hyperventilation, dizzinessetc (Rondung, 2016). Based on research data (Floris, 2017), the prevalence of mothers who experience anxiety and fear before birth there are about $10-50 \%$. This figure is not slight. So that intervention is needed so that mothers feel relaxed and calm in the face of labor that would not affect the complications of the delivery. Poor fetal wellbeing condition can even lead to postpartum depression. This labor pain will occur during the active phase of labor. As time passes, more cervical opening, thus the intensity of pain will be more frequent, and the duration will be longer. So we need skills in how to transfer labor pain and anxiety that occur by doing other activities. We expect maternity mothers can enjoy the process of delivery in a comfortable, relaxed manner so that labor can take place quickly, smoothly, and naturally (Surucu, 2018).

Mothers who experience excessive anxiety and fear of childbirth will increase the risk of postpartum depression and posttraumatic stress syndrome and will experience an increased response to labor pain compared to women who can undergo labor in a calm and relaxed manner. These will impact the labor progress, furthermore, the welfare of the fetus in the womb. Various factors such as physiological, psychological, and even environmental conditions affect women's labor pain perceptions. Physiological factors can be in the form of uterine contractions and cervical dilatation. Psychological factors such as anxiety, fear, community culture, and myth will affect the birth mother's psychological condition (Akadri, 2018). Women who can regulate their emotions and breathing well during labor will increase oxygenation to the fetus in the womb. Mother will feel comfortable, relaxed, confident, and believe the labor process will be smooth, convenient, natural, and normal. However, to transfer the pain of labor to other things and distract the mother's focus on the pain and labor contractions that come is not easy. Various interventions are needed to distract the mother from pain and labor contractions that come (Boaviagem, 2017): (Koelewijn, 2017).

Interventions are applied to reduce anxiety in the birth process. Among them is by listening to music Listening to music will divert the birth mother from the pain, the feeling of labor contractions that come, and the stress they experience by listening to the notes with a gentle and harmonious rhythm. Music can improve mood and reduce anxiety. Music can also cause physiological changes (decrease heart rate and breathing), increase relaxation. When the birth mother is happy and relaxes, the body will produce the endorphin hormone. Endorphine is a chemical such as morphine that can be produced naturally by the body. It has a role in helping to reduce pain and trigger positive feelings(Dolker, 2019). Given the limited options for pharmacological interventions for pregnant women, alternative, low-risk approaches to positive anxiety and stress are needed. In this case, the positive effect of music on anxiety and stress is an alternative that is often used (Hepp, 2018). The kind of music that can be used for therapy is gentle and regular music. One of which is instrumental music. Java-style music is one of the instrumental. The keroncong music genre is widely sung in the form of campursari and generally enjoyed as entertainment. Java-style has a tempo of 60 beats per minute. According to experts and researchers, the music or song with 60 beats per minute gives a relaxing effect.

Research related to Java-style musical influences on anxiety and pain in the active phase of the labor first stage is rare. An almost similar study has been done about the java music effect to decrease anxiousness in the elderly. The result is that there is a decrease in anxiety at 8:58 point (with a p-value of 0.000 / $\mathrm{p}>0.05$ ) between before given music style Java (mean 25.33) and after a given intervention (mean 16.8). Novelty freshness of this research is the method using the randomized controlled trial. The research objective was to analyze the effect of Java-style instrumental music on maternal anxiousness and pain in the labor primiparous active phase. 


\section{Method}

This research is an observational analytical research experiment with approaches randomized controlled trial (RCT). The design used was a completely randomized experimental design. In this design, all the subjects are directly allocated randomly into treatment or control groups. The population in this study are all the primiparous women giving birth in the active phase labor at Surakarta Hospital in September 2019-February 2020. There are 60 mothers giving birth. The sampling technique using randomization (simple random sampling). Subjects calculation in this study using a rule of thumb or 30 subjects each group (Murti, 2013). This study used 60 samples with a classification of 30 research subjects in each group given intervention Javanese style instrumental music and routine controlled by obstetric care. They are all maternal primiparity in the active phase of labor in Surakarta Hospital. The whole subjects have an equal opportunity of being selected into intervention and the only factor that determines the odds. Inclusion criteria for this study are pregnancy and childbirth in physiological conditions, labor active phase with the opening of $\leq 4 \mathrm{~cm}$ to $7 \mathrm{~cm}$, not hearimpaired, and do not use anesthesia during labor to reduce the pain of childbirth.

The data collection in anxiety measurement of mother postpartum is by STAI scale (The Spielberger State and Trait Anxiety Inventory). STAI is a measuring tool used to assess anxiety and validated for use in perinatal populations that began trimester during pregnancy up to 2 to 8 weeks postpartum visits. This instrument measures the separately momentary anxiousness (A-state) and basic anxiousness (A-trait) (Cox, 2015). STAI categorizes Anxiety into low and high. If the

Table 1. Characteristics of Research Subjects

\begin{tabular}{|c|c|c|c|c|c|}
\hline Characteristics & Criteria & $\mathbf{n}$ & $\%$ & $\mathbf{n}$ & $\%$ \\
\hline Age & $\begin{array}{l}<20 \text { years } \\
20-35 \text { years } \\
>35 \text { years }\end{array}$ & $\begin{array}{c}1 \\
29 \\
-\end{array}$ & $\begin{array}{c}3.3 \\
96.7 \\
-\end{array}$ & $\begin{array}{c}1 \\
28 \\
1\end{array}$ & $\begin{array}{c}3.3 \\
93.3 \\
3.3\end{array}$ \\
\hline Education & $\begin{array}{l}\text { Elementary-Junior High } \\
\geq \text { High School }\end{array}$ & $\begin{array}{l}19 \\
11\end{array}$ & $\begin{array}{l}63.3 \\
36.7\end{array}$ & $\begin{array}{l}19 \\
11\end{array}$ & $\begin{array}{l}63.3 \\
36.7\end{array}$ \\
\hline Profession & $\begin{array}{l}\text { Does not work } \\
\text { Work }\end{array}$ & $\begin{array}{l}13 \\
17\end{array}$ & $\begin{array}{l}43.3 \\
56.7\end{array}$ & $\begin{array}{l}18 \\
12\end{array}$ & $\begin{array}{l}60 \\
40\end{array}$ \\
\hline $\begin{array}{l}\text { Javanese style listening } \\
\text { experience }\end{array}$ & $\begin{array}{l}\text { Has never been } \\
\text { Ever }\end{array}$ & $\begin{array}{c}6 \\
24\end{array}$ & $\begin{array}{l}20 \\
80\end{array}$ & $\begin{array}{c}6 \\
24\end{array}$ & $\begin{array}{l}20 \\
80\end{array}$ \\
\hline
\end{tabular}

results of STAI $\leq 40$, then it is low. But if the results of STAI $>40$ belongs to the category of high anxiousness. The researcher uses Visual Analog Scale (VAS) scaling $0-100 \mathrm{~mm}$ ratio to measure Labor pain. VAS scoring is indicated by the distance between the tip line indicating no pain, to the point indicated by birth mothers. This scale gives full freedom to birth mothers to identify the severity of pain. Then researcher recorded the measurement results in the observation sheet.

\section{Results and Discussion}

The research subjects characteristics in Table 1 show that 30 research subjects in the intervention group given Javanese style music listening while 30 took routine midwifery care. The description of the variables is by characteristics, criteria, frequency, and percentage. In the group who listen to the music styles of Java and routine midwifery care, most respondents aged 20-35 years, for the group given the Javanese music as many as 29 respondents (96.7\%), and the routine midwifery care group were 28 respondents (93.3\%).

In the group given the Java-style music intervention, most respondents were elementary and junior high, respectively 19 respondents (63.3\%). For the occupation characteristics, most respondents were workers as many as 17 respondents (56.7\%). In the group given midwifery care routine, most respondents did not work as many as 18 respondents (60\%). For the Java-style music experience, most respondents had never listened to Java-style music. Whether in the group given the Javastyle music intervention nor the group given the midwifery care routine intervention. Each as many as 24 respondents ( $80 \%)$. 
The independent variable in this study is Java-style instrumental music, while the dependent variable is anxiety. Based on normality test data using the KolmogorovSmirnov test, the p-value is 0.016 (abnormal data distribution), so that the statistical tests used are different Mann-Whitney Test. Based on the difference between the group who listen to Java-style instrumental music with the group receiving routine midwifery care showed that p $0.000>0.05$ with a mean / average anxiety in those who listen to music at 33.9 Javanese style. While the mean value / average anxiety in the group given routine midwifery care higher at 37.9.

Table 2. Man Whitney Test Anxiety in the Group who Listen to the Java- style Music and Midwifery Care Routine

\begin{tabular}{lccccc}
\hline Variable Groups & n & mean & median & SD & p \\
\hline Anxiety (STAI) & & & & & \\
Javanese style instrumental music & 30 & 33.9 & 34.00 & 2.70 & 0000 \\
Midwifery care routine & 30 & 37.9 & 38.00 & 1.68 & \\
\hline
\end{tabular}

The independent variable in this study was the Javanese style instrumental music. Meanwhile, the dependent variable was labor pain. Based on the data normality test using the Kolmogorov-Smirnov, the p-value was 0.200 (normal data distribution), so the test statistic used was the Independent Samples T-Test. Based on the different tests between the groups given the Javanese style instrumental music and routine midwifery care, refer to labor pain during the active phase of the first stage, is obtained that sig. levene's test for equality of variances is equal to $0435>0.05$. It showed that the data variance between groups that listen to music instrumental style in Java with midwifery care group is homogenous or same routine.

Values of significance between the group given Javanese style instrumental music therapy with routine midwifery care was the $p$-value of $0.000>0.05$. The average value/mean of labor pain in the group given the Javanese music style intervention was equal to 64.83 . The average value/mean of labor pain was higher in the group given routine midwifery care. It was 76.13. It shows a significant difference and significant impact on labor pain between the group given Javanese style music listening intervention with a given group of midwifery care routine.

Table 3. Test Independent Samples T-Tests Labor Pain in Those Who Listen to the Music Style of Java and Midwifery Care Routine

\begin{tabular}{|c|c|c|c|c|c|c|c|}
\hline & Group & $\begin{array}{l}\text { mean } \\
(\mathrm{Mm})\end{array}$ & $\begin{array}{c}\text { mean } \\
\text { Difference }\end{array}$ & $\begin{array}{c}\text { median } \\
(\mathrm{Mm})\end{array}$ & SD & $\mathbf{t}$ & $\mathbf{p}$ \\
\hline \multirow{3}{*}{$\begin{array}{l}\text { Labor pain in } \\
\text { the active phase } \\
\text { of the first stage } \\
\text { of maternal } \\
\text { primipara }\end{array}$} & Java-style music & 64.83 & & 65.5 & & & \\
\hline & treatment & & -11.30 & & 8.99 & -4.54 & 0000 \\
\hline & $\begin{array}{l}\text { Midwifery Care } \\
\text { Routine }\end{array}$ & 76.13 & & 77.0 & $10: 23$ & & \\
\hline
\end{tabular}

Pregnant women who experience anxiety during childbirth used to be caused by fear. Fear of the stages in the process, pain during contractions, fear the delivery process will be long, and fear of the hospital environment. Anxiety increased when labor mothers would not get any touch, attention, and maternity care assistance (Floris, 2017). The high anxiousness experienced by the mother will have a direct impact on labor pain. The cortisol hormone is the stress hormone that affects the pain more intensely because of the inhibited secretion of endorphins (hormones that make mothers relaxed and calm and cozy).

One non-pharmacological therapy that can reduce anxiety during labor even until later during childbirth and prevent postpartum depression is music therapy. Music plays a significant role in human life. Music and music therapy contribute positive effects 
to a physiological condition, psychological, social, and emotional for those who listen. Appropriately selected music can reduce anxiety, promote relaxation, and relieve pain. Other effects are increase confidence and performance of health workers (Gokyildiz, 2018). The results showed a significant difference between the group given the javamusic style intervention with the group given routine midwifery care only. The difference in mother's anxiety in the first stage of the labor active-phase can be seen from the anxiousness mean/average value of 33.9 in the group given the Java-music styles intervention. While the routine midwifery care results mean/average of 37.9 and the significance p-value 0.000>0.05.

Music is a natural and convenient complementary therapy that can reduce labor anxiety and pain. It affects the nervous system of the right brain and causes psychophysiological responses through the limbic system. Physiologically, this mechanism can reduce the perception of labor pain because the body produces the hormones enkephalin and endorphin. Waves that occur in the brain can be accelerated and slowed by using music. Mothers who listen to music during the active phase of labor can help coordinate muscle tension and movement and create anxiolytic effects so that mothers will feel more comfortable and relaxed(Çelebi, 2020).

Music is the most delicate art form, yet very influential on the physical center and nerve tissue. It also affects the nervous system or the parasympathetic nervous system automatically, either directly or indirectly. Mozart's classical music has proven as a safe and effective therapy. Traditional Javanese gamelan music has a regular rhythm and soothing at 60-90 beats per minute. It is similar to the classical music of Mozart.

The characteristics of this type of music that can increase relaxation include having a regular speed of fewer than 80 beats per minute, dynamic music tone, the melody of the sound produced is smooth, soft, and flowing like instrumental music using the piano. Javanese music is a type of music that has soft tones and rhythms. This type of music rhythm has a variation of 60-75 beats per minute, has low to moderate notes, has a smooth and flowing melody, and has a soft tone quality. And based on the research results, listening to music can increase relaxation is in a minimum duration of 20-40 minutes. It should be consistently applied so that it will produce a far more optimal effect (Gonzalez, 2018).

Music with a regular rhythm has a calming effect on the soul, reduces stress, and distracts the pain and anxiety experienced during labor. Mothers who listen to music during labor can affect the nerve centers that regulate blood circulation and vasodilation. So this will have an impact on placental and uterine circulation which affects the well-being of the fetus. Based on research results(Dolker, 2019), the duration of time in listening to music effective to reduce anxiety and stress is at least 30 minutes. Pregnant women who listen to regular and gentle rhythm music will have a stable psychological and emotional condition. Her anxiousness and fear of childbirth decrease because music can affect the mother's breath and heart rate. The results are consistent with research about the decline in the level of anxiety in the elderly through the Javanese style of music therapy. There are significant differences between the groups listened to music style Java ( $\mathrm{p}=0.00, \alpha=0.05$ ), with a decrease in mean $8: 58$ or $14.3 \%$, and a significant reduction in the group not given java-style music intervention ( $\mathrm{p}=0: 01, \alpha=0.05$ ), with 2:04 mean reduction or $3.4 \%$.

Aligned with research titled "The effect of music on pain and anxiety of women in labor during reviews their first pregnancy, a study from Turkey" showed that after hours the first in the group given the music shows that statistically reduced pain compared with the group not given music therapy. Anxiety scores in the group given the music therapy after the exercise, the average score of anxiety becomes lower than the group who were not given and statistically has significant correlation (Surucu, 2018). Musical expression is closely related to "emotions, culture" such as movement, speech, and gestures. Because "emotional culture" is different, the relationship between the various elements of particular musical stimuli is also different. Javanese are tribes in Indonesia which is famous for its people calm demeanor and politeness are high. Javanese gamelan 
music player includes mental stability along with the audience, the beauty of this music lies in the music sounds pleasant and regularity of the rhythm. Music is a non-pharmacological therapy that is cheap, easy, not risky, and does not require special training so that the expectation of mothers who listen to music with regular rhythm will be able to help divert the pain of labor contractions so that fear and anxiety will decrease and the process of labor takes place smoothly and quickly (Redding, 2016)

Labor pain is affected by various factors. Among them are physiological factors such as uterine contractions, cervical dilatation, distention of the vagina, and perineum. Women who undergo induction in the delivery process will increase the pain response in the body. Factors such as age, parity, and gestational age at birth influence the perception of pain. Psychosocial factors i.e: culture, ethnicity, education level, and childbirth experience, can affect the response to pain. While anxiety, fear, and stress levels experienced by women even in the face of labor are no less important factors that affect pain in the respective ladies. In addition to factors related to the physiological and psychosocial of health service providers are very care and care in providing nonpharmacological therapy to help reduce the pain of childbirth include being a determining factor for a birth mother to feel comfortable during labor (McCauley, 2018),

Among the non-pharmacological therapies suggested for women in a giving-birth process to reduce their pain is traditional music therapy. Traditional music is ethnic music coming from every region and even tribes. This music has a regular rhythm so that it can create a state of relaxation and optimal rest. One of the traditional music with a relaxation effect is Java-style music. It is Java community music with a slow, soft tempo, and relaxed, to induce a calm feeling, and reduce muscle tension. The results showed no significant difference from the average/mean value between the group given the intervention of Java-style music has an average/mean labor pain value that is 64.83 . This value is lower than the group receiving the midwifery care routine intervention 76.13. These results were confirmed by the difference value of average/mean significant views of the p-value $0.000>0.05$.

Results are in line with research McCaffrey et al (2020) conducted based on the systematic review of 931 articles. The 24 were reviewed (12 of them by RCT, nine quasi-experiment, three research qualitative), where the research quality is quite good. Those articles showed music application during labor affecting pain, anxiety, psychological support, and accelerate the process (McCaffrey, 2020).

Another research conducted by (Rossi, 2018) mentioned that music affects the pain perception in the newborns' health status. In the study, 80 newborns in the hospital got three different interventions (three different types of music played). Meanwhile, 1 group was not. The result was that all three groups of babies who listened to music with these types of pauses (Mozart's sonata, Beethoven moonlights sonata, heartbeat sound recording) increased oxygen saturation, the heart rate became stable compared to the control group. With the statistical results $F=6.40$ with a p-value of 0.001 . Music stimulation performed on newborns for 2-3 days affected the baby's heart rate increase, respiratory rate, oxygen saturation, and reducing pain perception.

The music affects labor pain. The brain acts to change the physical condition of the body in response to the music. In relaxation music, the rhythm guides the body into breathing more slowly and deeply. So that it can provide a calming effect. Heartbeat and blood pressure also can respond to the music you listen to. Mental effects also depend on the type and the kind of music. Music can sharpen mental acuity or aid in relaxation. The music on human can affect the atmosphere better and help make the body move. The variety of music Psychiatric allows user to create a soothing feeling. Listening to music by using an audio recorder provides benefits to improve the health and welfare of the soul of the things that can suggest negative and positive effects to increase the physiological response (McCaffrey, 2020),

As described above, music makes women in the active phase of labor first stage enjoy it when the music played is proper. In acute and chronic pain, the psychological and 
emotional atmosphere gives a strong influence on the perception of pain is generated and the ability to cope. At the time listening to music will stimulate the pituitary gland to release endorphins to reduce pain. But it can change the negative perception about a process filled with traumatic childbirth.

\section{Conclusions}

Javanese style instrumental music therapy is effective in reducing maternal anxiety to primiparous active phase of the first stage of labor. The results of the analysis using a different test Man-Whitney significant difference and significant anxiety among the group given the music intervention style java compared with midwifery care routine with the results of significance p-value $0.000>0.05$ with a mean / average anxiety in those who listen Javanese style of music at 33.9. lower dibanidngkan with the group given routine midwifery care that is equal to 37.9. There are significant differences with p-values of $0.000>$ 0.05 for the pain of labor between the group given Javanese style instrumental music therapy with the one given routine midwifery care. The average/mean value of labor pain in the group given Java-style music intervention low at 64.83 , compared with the average/mean value in the group given routine midwifery care which is 76.13. Characteristics of research subjects the majority of respondents aged 20-35 years. So most respondents are within reproductive age and safe for pregnancy and give birth.

\section{References}

Abbasi, P., Mohammad-Alizadeh Charandabi, S., \& Mirghafourvand, M., 2020. Comparison of the Effect of Educational Software and Booklet on Anxiety and Pain During Labour: A Randomised Controlled Clinical Trial. Journal of Obstetrics and Gynaecology, 2020, pp.1-8.

Akadri, A.A., \& Odelola, O.I., 2018. Labour Pain Perception: Experiences of Nigerian mothers. Pan African Medical Journal, 30, pp.1-7.

Aksoy, H., Yücel, B., Aksoy, U., Acmaz, G., Aydin, T., \& Babayigit, M.A., 2016. The Relationship Between Expectation, Experience and Perception of Labour Pain: An Observational Study. SpringerPlus, 5(1).

Boaviagem, A., Melo- Junior, E., Lubambo, L., Sousa,
P., Aragão, C., Albuquerque, S., \& Lemos, A., 2017. The Effectiveness of Breathing Patterns to Control Maternal Anxiety During the First Period of Labor: A Randomized Controlled Clinical Trial. Complementary Therapies in Clinical Practice, 26, pp.30-35.

Çelebi, D., Yılmaz, E., Şahin, S.T., \& Baydur, H., 2020. The Effect of Music Therapy During Colonoscopy on Pain, Anxiety and Patient Comfort: A Randomized Controlled Trial. Complementary Therapies in Clinical Practice, 38, pp.1-6.

Cox, E.Q., Stuebe, A., Pearson, B., Grewen, K., Rubinow, D., \& Meltzer-Brody, S., 2015. Oxytocin and HPA Stress Axis Reactivity in Postpartum Women. Psychoneuroendocrinology, 55, pp.164-172.

Dolker, H.E., \& Basar, F., 2019. The Effect of Music on the Non-stress Test and Maternal Anxiety. Complementary Therapies in Clinical Practice, 35, pp.259-264.

Floris, L., Irion, O., \& Courvoisier, D., 2017. Influence of Obstetrical Events on Satisfaction and Anxiety During Childbirth: A Prospective Longitudinal Study. Psychology, Health and Medicine, 22(8), pp.969-977.

Gokyildiz, Surucu, S., Ozturk, M., Avcibay Vurgec, B., Alan, S., \& Akbas, M., 2018. The Effect of Music on Pain and Anxiety of Women During Labour on First Time Pregnancy: A Study from Turkey. Complementary Therapies in Clinical Practice, 30, pp.96-102.

Gonzalez, J.G., Ventura-Miranda, M.I., RequenaMullor, M., Parron-Carreño, T., \& AlarconRodriguez, R., 2018. State-trait Anxiety Levels During Pregnancy and Foetal Parameters Following Intervention with Music Therapy. Journal of Affective Disorders, 232, pp.1722.

Hepp, P., Hagenbeck, C., Gilles, J., Wolf, O.T., Goertz, W., Janni, W., Balan, P., Fleisch, M., Fehm, T., \& Schaal, N.K., 2018. Effects of music intervention duringcaesarean delivery on anxiety and stress ofthe mother a controlled, randomised study. BMC Pregnancy and Childbirth. 18(1), pp.435-442.

Koelewijn, J.M., Sluijs, A.M., Vrijkotte, \& T.G.M., 2017. Possible Relationship Between General and Pregnancy-related Anxiety During the First Half of Pregnancy and the Birth Process: A Prospective Cohort Study. BMJ Open, 7(5).

McCaffrey, T., Cheung, P.S., Barry, M., Punch, P., \& Dore, L., 2020. The Role and Outcomes of Music Listening for Women in Childbirth: An Integrative Review. Midwifery, 83. 
McCauley, M., Actis Danna, V., Mrema, D., \& Van Den Broek, N., 2018. We Know It's Labour Pain, So We Don't Do Anything": Healthcare Provider's Knowledge and Attitudes Regarding the Provision of Pain Relief During Labour and After Childbirth. BMC Pregnancy and Childbirth, 18(1), pp.1-9.

Murti, B., 2013. Desain Dan Ukuran Sampel Untuk Penelitian Kuantitatif Dan Kualitatif Di Bidang Kesehatan. Yogyakarta: Gadjah Mada University Press.

Rados, S.N., Tadinac, M., \& Herman R., 2018. Anxiety During Pregnancy and Postpartum: Course, Predictors and Comorbidity with Postpartum Depression. Acta Clinica Croatica, 57(1), pp. 39.51.

Redding, J., Plaugher, S., Cole, J., Crum, J., Ambrosino, C., Hodge, J., \& Cowan, L., 2016. "Where's the Music?" Using Music Therapy for Pain Management. Federal Practitioner : for the Health Care Professionals of the VA, DoD, and PHS, 33(12), pp.46-49.

Rondung, E., Thomten, J., \& Sundin, O., 2016. Psychological Perspectives on Fear of Childbirth. Journal of Anxiety Disorders, 44, pp. 80-91.

Rossi, A., Molinaro, A., Savi, E., Micheletti, S., Galli, J., Chirico, G., \& Fazzi, E., 2018. Music Reduces Pain Perception in Healthy Newborns: A Comparison Between Different Music Tracks and Recoded Heartbeat. Early Human Development, 124, pp.7-10.

Surucu, G.S., Ozturk, M., Avcibay Vurgec, B., Alan, S., \& Akbas, M., 2018. The Effect of Music on Pain and Anxiety of Women During Labour on First Time Pregnancy: A Study from Turkey. Complementary Therapies in Clinical Practice, 30, pp.96-102. 